Research Article

\title{
Modeling Static Behavior of Rockfill Materials Based on Generalized Plasticity Model
}

\author{
Shihai Bian $\mathbb{D}^{1},{ }^{1}$ Bo Wu $\mathbb{D}^{1,2}$ and Yongzheng $\mathrm{Ma} \mathbb{D i D}^{2,3}$ \\ ${ }^{1}$ College of Civil Engineering and Architecture, Guangxi University, Nanning 530004, China \\ ${ }^{2}$ Engineering Research Center of Industrial Construction in Civil Engineering of Zhejiang, Ningbo \\ University of Technology, Ningbo 315016, China \\ ${ }^{3}$ School of Civil and Transportation Engineering, Ningbo University of Technology, Ningbo 315016, China \\ Correspondence should be addressed to Bo Wu; wubo@gxu.edu.cn
}

Received 15 July 2019; Accepted 10 August 2019; Published 8 September 2019

Academic Editor: Tayfun Dede

Copyright (C) 2019 Shihai Bian et al. This is an open access article distributed under the Creative Commons Attribution License, which permits unrestricted use, distribution, and reproduction in any medium, provided the original work is properly cited.

\begin{abstract}
Rockfill materials are commonly used for dam construction. Establishing an effective model that can reasonably describe the mechanical properties of rockfill material is very important for the calculation of earth-rock dam engineering. Based on the generalized plasticity model of sand, a modified generalized plasticity model suitable for rockfill material is established by modifying the plastic modulus. Focusing on three types of stress paths (e.g., CT test, CP test, and CR test), the stress path adaptability of the modified generalized plasticity is studied. Simulation results show that the proposed model can well predict the strength characteristics while it underestimates the shrinkage characteristics of rockfill materials for constant P test. It is difficult for the generalized plasticity model to predict larger radial shrinkage strain for constant stress ratio tests. This shortcoming can be improved by employing a modified dilatancy equation. Finally, by introducing critical state theory and considering the effect of initial void ratio on plastic modulus, a state-dependent generalized plasticity model is proposed and verified by experiment of granite rockfill materials and TRM with different void ratios. These works covers the most common stress paths related to the construction of earth-rock dams and can capture static behavior of rockfill materials.
\end{abstract}

\section{Introduction}

Earth-rock dams are widely built in the world for their good adaptability to foundation conditions, full use of building excavation materials, and low cost. As the main material for dam construction, the stress-strain characteristics of rockfill materials become quite complex with the increasing height of earth-rock dam construction. The constitutive relationship of rockfill materials becomes a key problem in the calculation and analysis of earth-rock dam. In recent years, Dalian University of Technology has developed the generalized plasticity model, which is applied to the static and dynamic analysis of Zipingpu concrete face dam $[1,2]$, making the generalized plasticity model an important constitutive model in the static and dynamic calculation of earth-rock dam.

Wei and Zhu [3] developed an elastoplastic model within the framework of the generalized plasticity theory and applied the model to analyze the deformation of the Shuibuya concrete-faced rockfill dam. Dong et al. [4] made a comparison between Duncan and Chang's EB Model and the generalized plasticity model in the analysis of a high earthrockfill dam. Fu et al. [5] deduced the explicit plastic modulus expression of triaxial loading/unloading process in a framework of generalized plasticity and modeled the cyclic behavior of rockfill materials. Goorani and Hamidi [6] developed a generalized plasticity model to predict the mechanical behavior of sand-gravel mixtures. Liu and Gao [7] proposed a generalized plasticity model for coarse-grained materials by considering the effect of particle breakage on their critical state behavior. Cen et al. [8] presented a modified generalized plasticity model for sand considering a refined description of the pressure-dependent critical void ratio and described sand behavior under different densities and confining pressures. Abioghli and Hamidi [9] modified generalized plasticity 
model to simulate the mechanical behavior of fiber reinforced cemented sand. These studies are of great value in describing the mechanical properties of coarse-grained materials by generalized plasticity model.

For earth-rock dam engineering, it is necessary to develop a simple and effective model which can capture key characteristic of rockfill materials. Such a model will improve numerical calculation level of earth-rock dam engineering and of great significance to understand mechanical properties of rockfill materials. In this paper, a simple modified generalized plasticity model will be proposed. By comparing the results of conventional triaxial tests and predictions, the rationality of the model is verified. The adaptability of the model under complex stress paths is further studied and extended to state-dependent situations.

\section{Modified Generalized Plasticity Model}

2.1. Prediction Results of Sand Generalized Plasticity Model. This paper chooses the original generalized plasticity model [10] and the unified generalized plasticity model of sandy soil proposed by Ling and Yang [11] to predict the triaxial loading test and verifies the adaptability of the generalized plasticity model of sandy for the rockfill triaxial test under high confining pressure. The test data are derived from the triaxial experiment of Rumei rockfill under $3200 \mathrm{kPa}$ confining pressure. Rumei rockfill materials sample were collected from Rumei hydropower station, which located in Rumei town, Mangkang county, Tibet, China.

Firstly, the original generalized plasticity model [10] is used to simulate the triaxial test of Rumei rockfill under $3200 \mathrm{kPa}$ confining pressure. Under the condition of same transformation stress ratio $M_{\mathrm{g}}$, different values of $\beta_{0}$ and $\beta_{1}$ are taken, respectively. The simulation results are shown in Figure 1. It can be seen that if the expression of the loading plastic modulus is the original generalized plastic modulus expression, no matter how to adjust the value of $\beta_{0}$ and $\beta_{1}$ in the simulation process, the curve simulated in the initial stage always deviates from the actual one; that is, the deviating stress increases too fast in the initial stage and grows too slowly or decreases excessively in the later stage.

The general plasticity model proposed by Ling and Yang [11] is also used to simulate triaxial compression of Rumei rockfill under confining pressure of $3200 \mathrm{kPa}$. The simulation result is compared with the original generalized plasticity model and the following modified model in Figure 2. It can be seen that Ling's model [11] is still difficult to predict that the deviation stress increases linearly with the axial strain in the initial process of triaxial test reasonably.

Thus, in order to better simulate the mechanical properties of rockfill under triaxial loading, especially under high confining pressure, the generalized plasticity model of sand may need some modification.

\subsection{Description of Modified Generalized Plasticity Model.} In the framework of generalized plasticity model [10], loading direction, flow direction, plastic modulus, elastic bulk modulus, and elastic shear modulus are explicitly

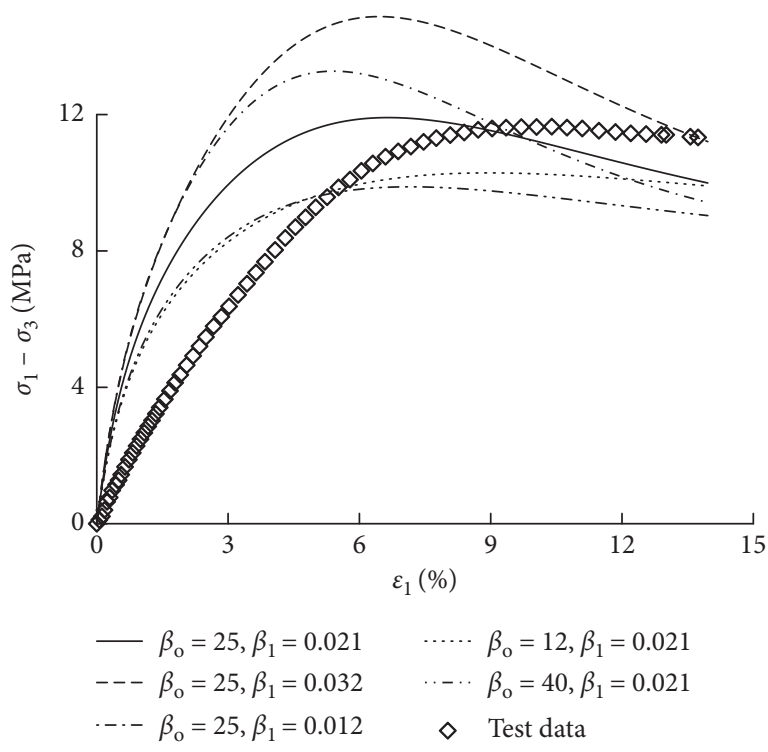

FIGURE 1: Simulation results of original generalized plasticity model.

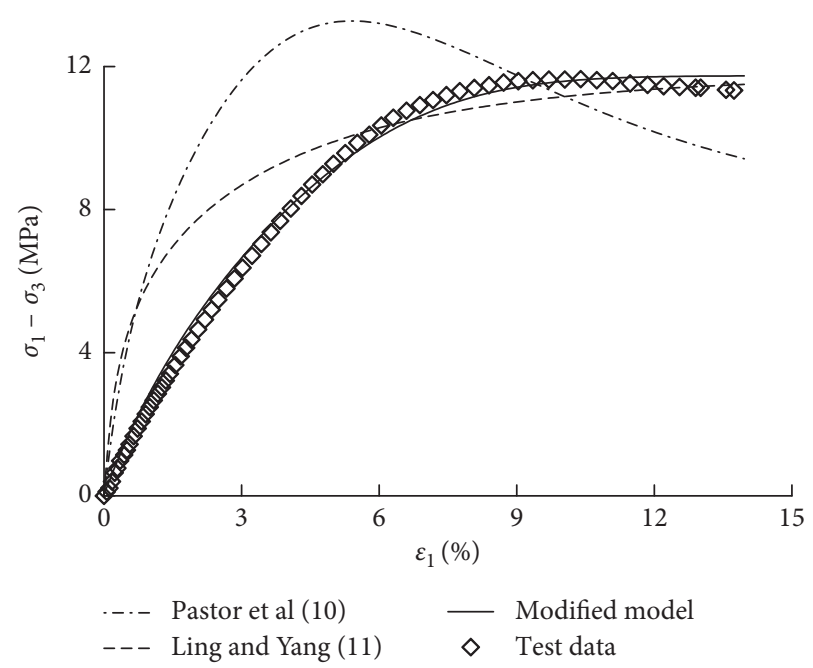

FIGURE 2: Comparison of the original model and model proposed by Ling et al.

defined. Many scholars have improved the plastic modulus [12-14]. The modified generalized plasticity model proposed in this paper is mainly based on the original generalized plasticity model [10]. The relevant description of the modified model is as follows.

In the elastic-plastic model, the increment of stress and strain has the following relationship:

$$
d \sigma=\mathbf{D}^{\mathrm{ep}} d \varepsilon
$$

In the original generalized plasticity model [10], the elastic-plastic stiffness matrix $\mathbf{D}^{\mathrm{ep}}$ in the generalized plasticity model is defined as follows:

$$
\mathbf{D}^{\mathrm{ep}}=\mathbf{D}^{\mathrm{e}}-\frac{\left(\mathbf{D}^{\mathrm{e}}: n_{\mathrm{g}}\right) \otimes\left(n_{\mathrm{f}}: \mathbf{D}^{\mathrm{e}}\right)}{H+n_{\mathrm{f}}: \mathbf{D}^{\mathrm{e}}: n_{\mathrm{g}}},
$$

where $n_{\mathrm{g}}$ is plastic potential flow direction, $n_{\mathrm{f}}$ is loading direction, $H$ is loading and unloading plastic modulus, $\mathbf{D}^{\mathrm{e}}$ is 
elastic matrix, and $\mathrm{D}^{\mathrm{ep}}$ is elastic-plastic matrix. The symbol of " $\otimes$ " is Kronecker product of tensor, and the symbol of “:” is matmul product of tensor.

Defining plastic flow and loading direction as

$$
\begin{aligned}
& n_{\mathrm{g}}=\left(\frac{d_{\mathrm{g}}}{\sqrt{1+d_{\mathrm{g}}^{2}}}, \frac{1}{\sqrt{1+d_{\mathrm{g}}^{2}}}\right), \\
& n_{\mathrm{f}}=\left(\frac{d_{\mathrm{f}}}{\sqrt{1+d_{\mathrm{f}}^{2}}}, \frac{1}{\sqrt{1+d_{\mathrm{f}}^{2}}}\right),
\end{aligned}
$$

where $d_{\mathrm{g}}$ and $d_{\mathrm{f}}$ are defined similar to original generalized plasticity model:

$$
\begin{aligned}
d_{\mathrm{g}} & =(1+\alpha)\left(M_{\mathrm{g}}-\eta\right), \\
d_{\mathrm{f}} & =(1+\alpha)\left(M_{\mathrm{f}}-\eta\right), \\
M_{\mathrm{f}} & =M_{\mathrm{f} 0}\left(\frac{p}{p_{\mathrm{c}}}\right)^{-n},
\end{aligned}
$$

where $M_{\mathrm{f}}$ is the stress ratio of peak strength, $M_{\mathrm{g}}$ is the phase transformation stress ratio, and $p_{c}$ is the reference stress for breakage. After determining $p_{\mathrm{c}}, M_{\mathrm{f} 0}$, and $n$ can be obtained by fitting the peak strength under different confining pressures. Similar as Zou et al. [15], the following forms of elastic shear modulus and bulk modulus are adopted in the modified model:

$$
\begin{aligned}
& G=G_{0} p_{\mathrm{a}}\left(\frac{p}{p_{\mathrm{a}}}\right)^{0.5}, \\
& K=\frac{2(1+v)}{3(1-2 v)} G,
\end{aligned}
$$

where $G_{0}$ is material parameters, $p$ is average pressure, and $v$ is Poisson's ratio.

From Section 2.1, the plastic modulus of the original model [10] and Ling's model [11] under high confining pressures needs further modification. By comparing the predicted results with the experimental results, it is found that the main reason for large deviation is the unreasonable expression of the plastic modulus, which is larger at the initial stage of loading and smaller at the later stage of loading, especially under the condition of high confining pressure. To improve this shortcoming and considering the reasonable pressure dependence of plastic modulus, the revised coefficients $H_{1}$ and $H_{2}$ were introduced to modify the plastic modulus, and the modified plastic modulus expression is given as follows:

$$
H=H_{0} p_{\mathrm{a}}\left(\frac{p}{p_{\mathrm{a}}}\right)^{\mathrm{m}} H_{1} H_{2} \text {. }
$$

In equation (6), the revised coefficients $H_{1}$ and $H_{2}$ are defined as

$$
\begin{aligned}
& H_{1}=1-\left(\frac{\eta}{M_{\mathrm{f}}}\right)^{\beta}, \\
& H_{2}=\exp \left(\frac{\gamma \eta}{M_{\mathrm{f}}}\right),
\end{aligned}
$$

where $m, \beta$, and $\gamma$ are model parameters, which need to be determined according to the $q-\varepsilon_{\text {a }}$ curve of rockfill experiments under different confining pressures. The revised coefficient $H_{1}$ is introduced to improve the defect that the deviating stress increases too fast in the initial stage, and $\mathrm{H}_{2}$ is used to modify the defect that deviating stress increases too slowly or decreases excessively in the later stage.

2.3. Model Verification. Liu et al. [16] simulated the deformation characteristics of diorite rockfill materials under four confining pressures of triaxial test. Although the plastic modulus was also modified, the prediction results of the strength of rockfill were relatively unsatisfactory. In this section, the modified generalized plasticity model was used to simulate again to verify the rationality and prediction effect of the model. Besides diorite rockfill materials test, triaxial compression experiments of Gushui rockfill with $16.2 \%$ void ratio and Sanbanxi rockfill materials are also validated.

The model parameters can be divided into three categories: elastic parameters $\left(G_{0}\right.$ and $\left.v\right)$, dilatancy, and strength parameters $\left(n, \alpha, M_{\mathrm{g}}, M_{\mathrm{f} 0}\right.$, and $\left.p_{\mathrm{c}}\right)$ and plastic modulus parameters $\left(H_{0}, m, \beta\right.$, and $\left.\gamma\right)$. Suggested by Xiao et al. $[17,18]$, elastic modulus parameters can be determined by the initial stage of triaxial test (i.e., the axial strain limited to $0.2 \%$ ) at various densities or pressures from the test data of rockfill materials in terms of the relationship between the deviatoric stress $q$ and the deviatoric strain $\varepsilon_{s}$.

Since it can be assumed that $d_{\mathrm{g}}=d \varepsilon_{\mathrm{v}}^{\mathrm{p}} / d \varepsilon_{\mathrm{s}}^{\mathrm{p}} \approx d \varepsilon_{\mathrm{v}} / d \varepsilon_{\mathrm{s}}$, dilatancy parameters can be determined by sorting out the shear dilatancy equation curve $d_{\mathrm{g}} \sim \eta$. Strength parameters can be obtained by fitting the peak strength curve $M_{\mathrm{f}} \sim p / p_{\mathrm{c}}$ of rockfill materials experiment under different confining pressures.

In isotropic compression test, correction factors $H_{1}$ and $H_{2}$ are equal to 1 due to $\eta=0$, and the plastic modulus expression can be degenerated into

$$
H=H_{0} p_{\mathrm{a}}\left(\frac{p}{p_{\mathrm{a}}}\right)^{\mathrm{m}} \text {. }
$$

For the plastic modulus parameters, $H_{0}$ and $m$ can be determined by using the isotropic compression experimental curve. The parameters $\beta$ and $\gamma$ are calibrated by matching the predicted results with the curves of triaxial tests under different confining pressures. Due to the lack of isotropic compression test data, the plastic modulus parameters of rockfill test are determined by IGA algorithm [19]. From the simulation results of a large number of rockfill materials, the value of $\beta$ is usually between 0.1 and 0.9 , and $\gamma$ is always between 0 and 2 .

The parameters of the modified generalized plasticity model determined by the three groups of conventional triaxial tests are listed in Table 1 . The predicted results of the three groups of conventional triaxial tests can be seen in Figures 3-5.

By comparing prediction results and the test results of three groups' materials, it can be seen that the modified 
TABLE 1: Constitutive model parameters of three different rockfill materials.

\begin{tabular}{lcccccccccccc}
\hline \multirow{2}{*}{ Parameters } & \multicolumn{3}{c}{ Plastic modulus parameters } & \multicolumn{3}{c}{ Elastic } & \multicolumn{3}{c}{ Shear dilatancy and strength parameters } \\
& $H_{0}$ & $m$ & $\beta$ & $\gamma$ & $G_{0}$ & $v$ & $M_{\mathrm{f} 0}$ & $n$ & $\alpha$ & $M_{\mathrm{g}}$ & $p_{\mathrm{c}}(\mathrm{kPa})$ \\
\hline Diorite RM & 953 & 0.45 & 0.14 & 2.0 & 637 & 0.2 & 1.59 & 0.11 & -0.1 & 1.80 & 4800 \\
Sandstone RM & 1849 & 0.41 & 0.24 & 1.6 & 462 & 0.2 & 1.899 & 0.134 & 0.2 & 1.71 & 3600 \\
Sanbanxi RM & 2504 & 0.455 & 0.254 & 1.2 & 655 & 0.2 & 1.70 & 0.155 & -0.37 & 1.94 & 3800 \\
\hline
\end{tabular}

generalized plasticity model improves the situation mentioned in Section 2.1 that the deviating stress increases faster in the early stage and slower in the later stage. The proposed model reasonably predicts the stress-strain relationship of rockfill under conventional triaxial loading. The simulation results of diorite rockfill test with modified generalized plasticity model are also better than those of critical state model proposed by Liu et al.

\section{Study on the Adaptability of the Model under Different Stress Paths}

3.1. Necessity of Study on Stress Path Adaptability. In above section, the research on the stress-strain behavior of rockfill materials is mainly based on the conventional triaxial test. The stress path of rockfill materials is different from the actual stress path of rockfill material during dam construction and water storage. However, the deformation characteristics of rockfill materials have obvious stress path correlation during dam filling and impoundment [20]. Taking the field-measured results of earth pressure gauge of Sanbanxi concrete face dam as an example, Figure 6 shows the filling process of Sanbanxi rockfill dam, and Figure 7 shows the monitoring results of vertical and horizontal stresses of four groups of stress gauges during the filling and operation of the dam [21]. It can be seen from Figure 7 that most elements of the dam exhibit the stress path of equal stress ratio in the filling process. Therefore, it is necessary to verify the adaptability of the constitutive model of rockfill materials under different stress paths.

In the application of the generalized plasticity model in rockfill materials, besides the generalized plasticity model proposed by Zou et al. [15], the typical models include unified generalized plasticity model [12] and elastoplastic model considering particle breakage [13]. These three models are different in the constructing plastic modulus and are widely used in the prediction of rockfill materials behavior. Currently, only Zou et al. [15] and Wei and Zhu [3] validate the adaptability of the generalized plasticity model under different stress paths. However, two different types of experiments were validated, and there was lack of comparison for one particular experiment. Wang et al. [14] used the generalized plasticity model considering particle breakage to predict three kinds of stress path tests of rockfill materials of Yixing pumped storage power station, but only a set of equal stress ratio tests were validated. In the validated equal stress ratio tests, the corresponding equal stress ratio is very large

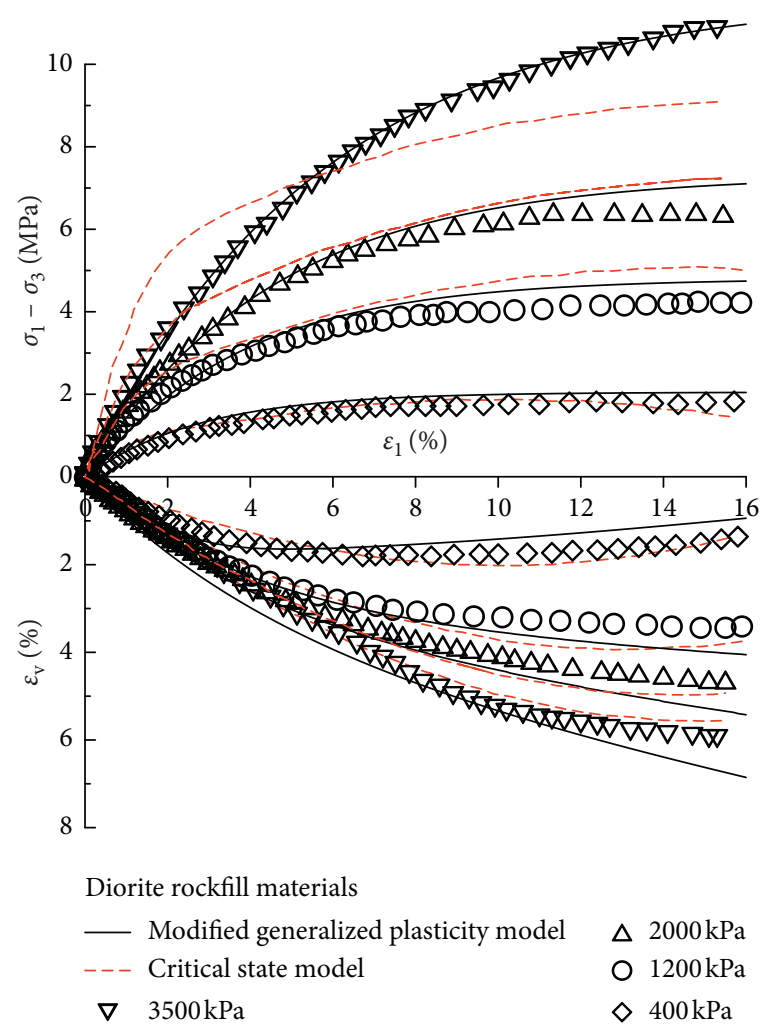

FIGURE 3: Comparisons between test results and prediction results of two models.

( $\left.R=d \sigma_{1} / d \sigma_{3}=8\right)$, which is relatively close to the triaxial loading $(R=\infty)$. It is actually not conducive to find adaptability law of such model under different stress paths.

In general, the study on the adaptability of generalized plasticity models under stress paths is not enough. In order to deeply analyze and reveal adaptability law of generalized plasticity models, an adaptability study of generalized plasticity model under various stress paths is made.

3.2. Prediction of Conventional Triaxial Test. For the modified generalized plasticity model, according to the test data of Yang et al. [22], the values of parameters such as $\alpha, M_{\mathrm{g}}, M$, $n, G_{0}, p_{c}$ can be obtained by sorting out conventional triaxial loading test data. Due to the lack of isotropic compression test data, the corresponding parameters such as $\beta, \gamma, m, H_{0}$ are determined by fitting the stress-strain curve of triaxial test and using IGA (immune genetic algorithm). The specific parameters of the model are shown in Table 2. 


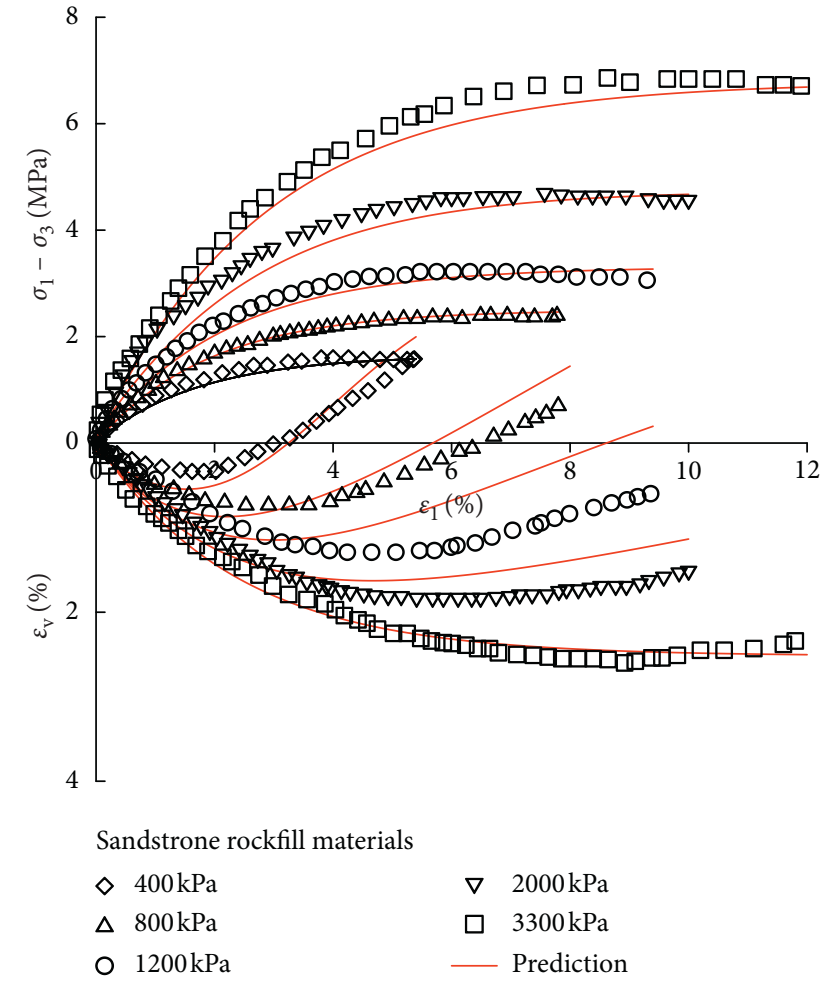

FIgURE 4: Sandstone rockfill materials experiment results and model prediction.

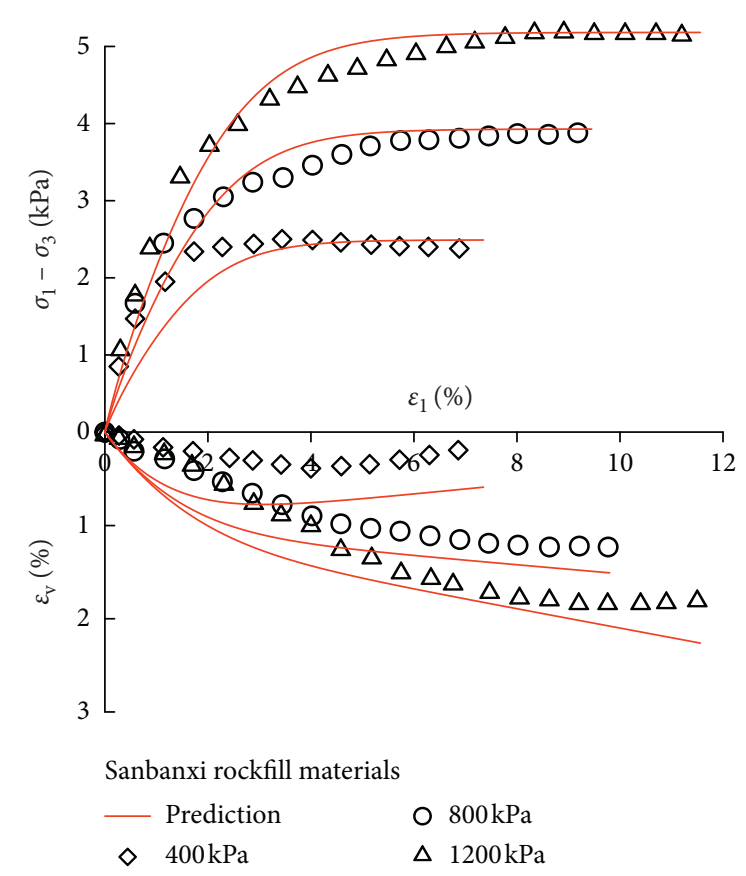

FIGURE 5: Sanbanxi rockfill materials experiment results and model prediction.

For these two types of models, if $\eta>M_{\mathrm{f}}$, then $\eta=0.99 M_{\mathrm{f}}$, to ensure that the Fortran program can be implemented smoothly. There are three types of experiments involved in Yang et al. [22]: conventional triaxial test, constant $\mathrm{P}$ test, and constant stress ratio test. These three types of experiments are abbreviated as CT, CP, and CR test accordingly, and the illustration of three types of experiments can be seen in Figure 8. The triaxial test predicted by generalized plasticity model is shown in Figure 9. From the simulation results, it can be seen that the generalized plasticity model can well simulate the stress-strain response of rockfill under conventional triaxial loading. The generalized plasticity model predicted slightly stronger dilatancy under low confining pressure in experiment.

3.3. Validation and Comparison of Other Stress Path Adaptability. The parameters obtained by conventional triaxial tests are also used to validate CP tests under four confining pressures (mean stress is constant, deviating stress is increasing until failure, $\Delta \sigma_{1} / \Delta \sigma_{3}=-2$ ) and 4 groups of CR tests (simultaneous axial and radial loading, $\Delta \sigma_{1} / \Delta \sigma_{3}=R$ ).

3.3.1. CP Test. The parameters of modified model are calibrated by CT tests data by combining the approach in Section 2.3. Generalized plasticity models are used to predict the CP tests under four confining pressures, respectively. The predicted results are shown in Figure 10. For CP test of rockfill materials, the confining pressure decreases continuously during the increase of deviation stress, which makes the lateral restraint of the specimen decrease continuously and is conducive to the occurrence of dilatancy, so volumetric strain change will be significantly smaller than that of the conventional triaxial test under the same confining pressure. From Figure 10, it can be seen that the generalized plasticity model can predict the strength characteristics of rockfill materials very well, and the predicted volumetric strain is smaller than that under the corresponding conventional triaxial loading, which conforms to the basic rule of CP test. However, the volumetric strain predicted by the generalized plasticity model is much smaller than the experimental values. It indirectly shows that the dilatancy law of CP test under the same confining pressure is different from that of CT test. The dilatancy equation of constant $\mathrm{P}$ test is different from that of conventional triaxial test. It is actually a nonlinear dilatancy equation for CP test. The nonlinear dilatancy equation has been employed to predict the experiment result of $\mathrm{P}$ test, but the result is still unsatisfactory. The key to solve this issue may lie in the plastic modulus. Perhaps the current formula of plastic modulus is still not effective enough. This issue deserves further study.

Generally speaking, the generalized plasticity model can predict the strength characteristics of rockfill of CP test. However, if the parameters of CT test are used, the model may underestimate the shrinkage characteristics of rockfill under CP test and predict smaller shrinkage deformation. The modified generalized plasticity model can hardly predict strain response under simultaneous radial loading and axial unloading effectively.

3.3.2. CR Test. The constant stress ratio path is a kind of stress path which deserves attention in the actual 


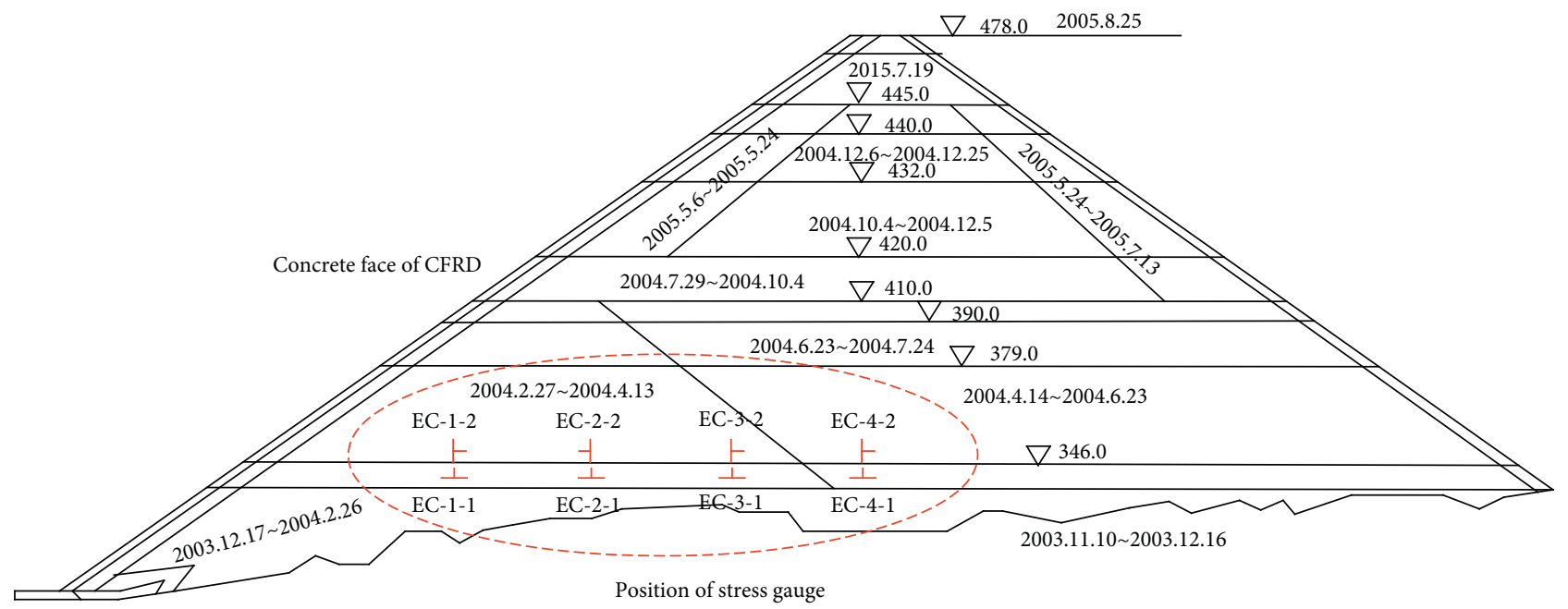

FIGURE 6: Filling process and stress gauge location of typical section of Sanbanxi Rockfill Dam (data from [21]).

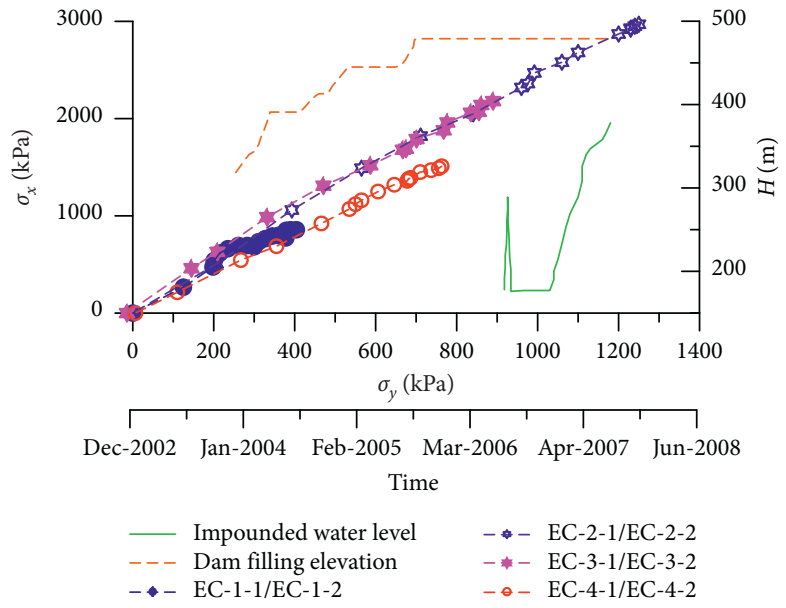

Figure 7: Stress gauge monitoring results of Sanbanxi Rockfill Dam (data from [21]).

TABle 2: Modified general plasticity model parameters.

\begin{tabular}{lccccccccccc}
\hline Material & $\alpha$ & $\beta$ & $M_{\mathrm{g}}$ & $M$ & $n$ & $G_{0}$ & $H_{0}$ & $m$ & $v$ & $\gamma$ & $p_{\mathrm{c}}(\mathrm{kPa})$ \\
\hline Granite RM & 0.4 & 0.19 & 1.652 & 1.547 & 0.11 & 540 & 8460 & 0.74 & 0.3 & 2.0 & 3800 \\
\hline
\end{tabular}<smiles>COC1CC(O)CC(OCC(C)(C)C)C1</smiles>

For CT test: $\Delta \sigma_{3}=0$

For CP test: $R=\Delta \sigma_{1} / \Delta \sigma_{3}=-2$

For CR test: $R=\Delta \sigma_{1} / \Delta \sigma_{3}=1.5,2.0,2.5,3.5$

FIGURE 8: Illustration of three types of experiments involved in Yang et al. [22].

construction of rockfill materials. Four CR tests are predicted using conventional triaxial test parameters. Constant stress ratio $\left(R=\Delta \sigma_{1} / \Delta \sigma_{3}\right)$ corresponds to four
CR test are 1.5, 2.0, 2.5, and 3.5, respectively. Variations of the mean stress $p$ with volumetric strain $\varepsilon_{\mathrm{v}}$, the deviatoric stress $q$ with deviatoric strain $\varepsilon_{\mathrm{s}}$, the volumetric strain $\varepsilon_{\mathrm{v}}$ with axial strain $\varepsilon_{1}$, and the radial strain $\varepsilon_{3}$ with axial strain $\varepsilon_{1}$ are predicted. Figure 11 shows the predicted results of the modified generalized plasticity model.

For the generalized plasticity model, the prediction results of the volumetric strain $\varepsilon_{\mathrm{v}}$ with axial strain $\varepsilon_{1}$, the radial strain $\varepsilon_{3}$ with axial strain $\varepsilon_{1}$ exist certain deviations from the experimental results if the dilatancy equation under conventional triaxial conditions is adopted. Meanwhile, the simulation results of the generalized plasticity model under high stress ratio path is obviously better than that of low stress ratio test, which indicates good adaptability for high stress ratio test. 


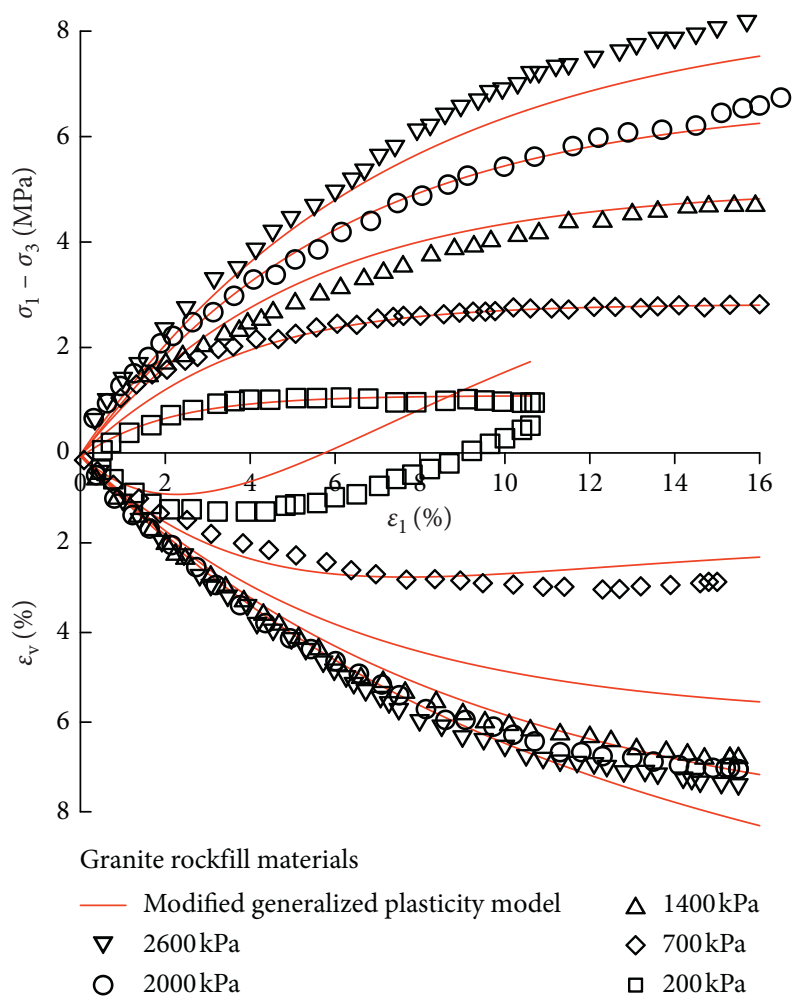

FIgURE 9: Predicted results of CT test using modified generalized plasticity model.

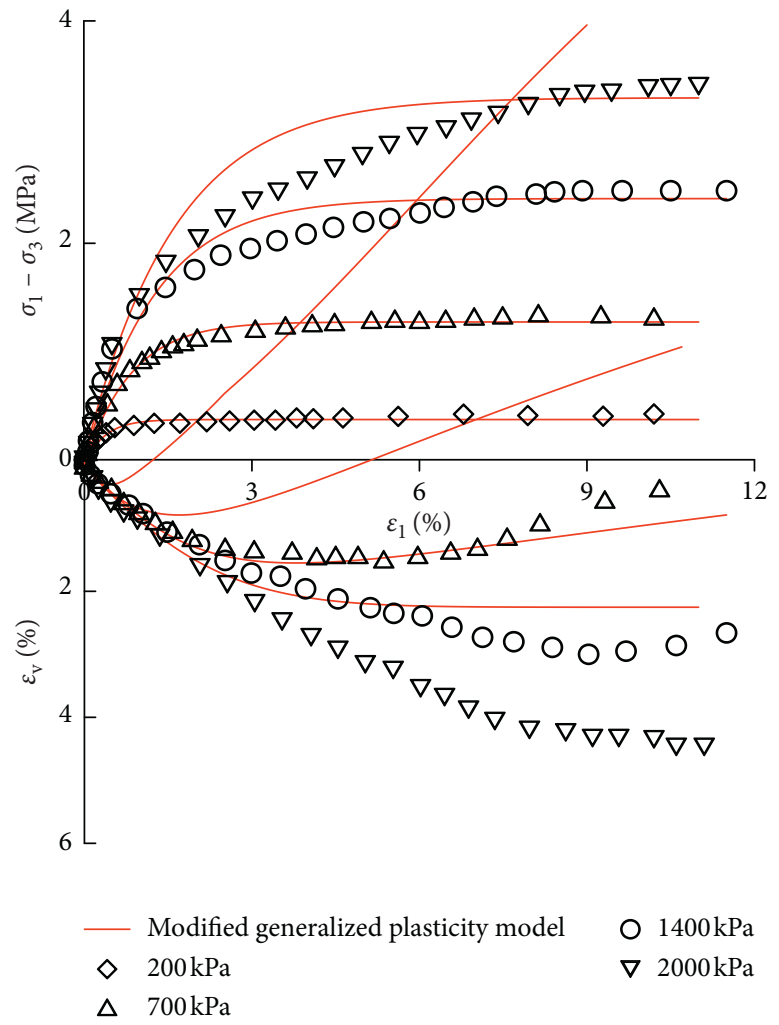

FIgURE 10: Predictions of modified generalized plasticity model for CP test.

It can be seen from Figure 11(d) that the generalized plasticity model is less accurate in predicting radial strain. It is difficult for the generalized plasticity model to predict larger radial shrinkage strain. With the increase of constant stress ratio, the radial deformation of triaxial test changes rapidly from radial shrinkage to radial expansion. This 

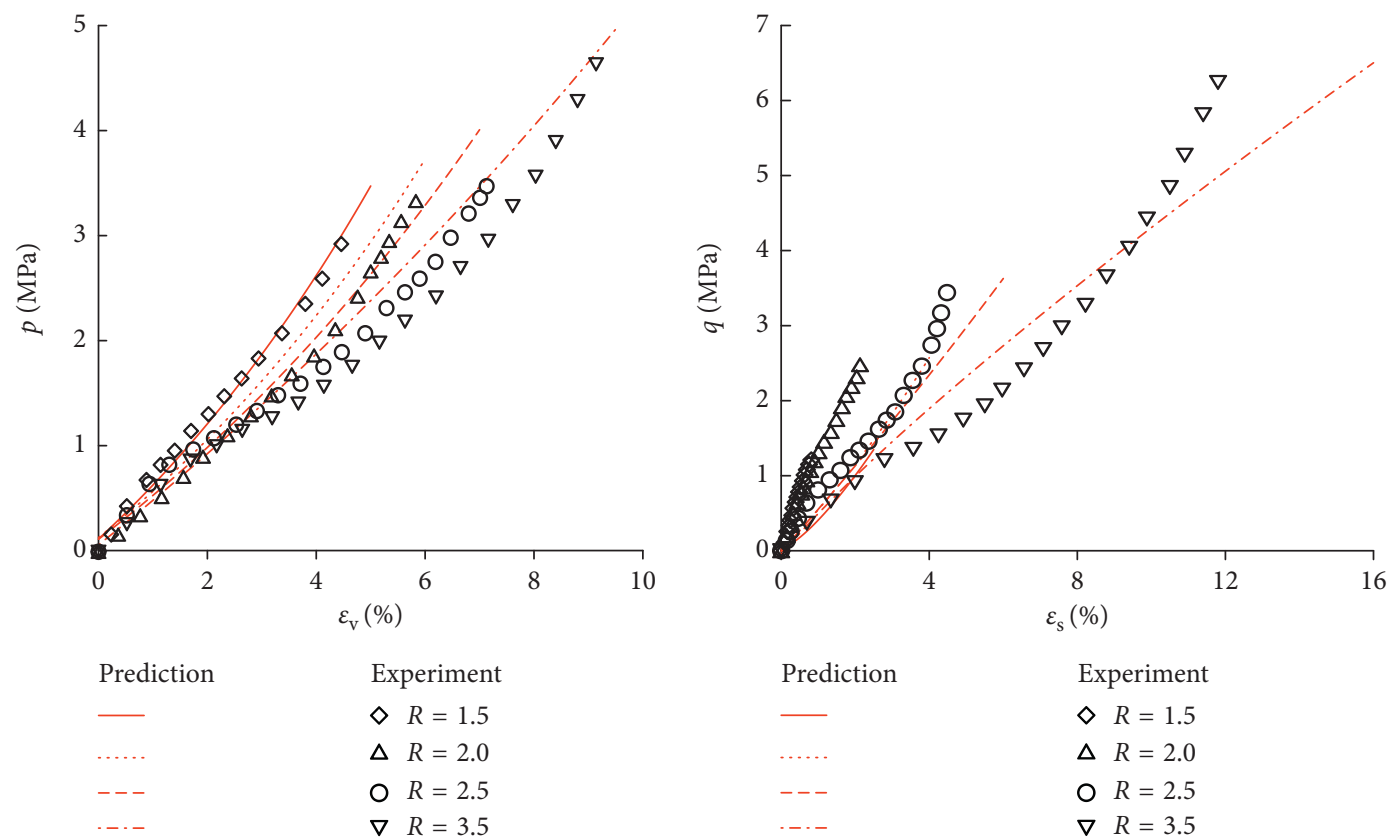

(a)

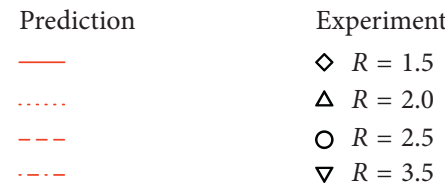

(b)
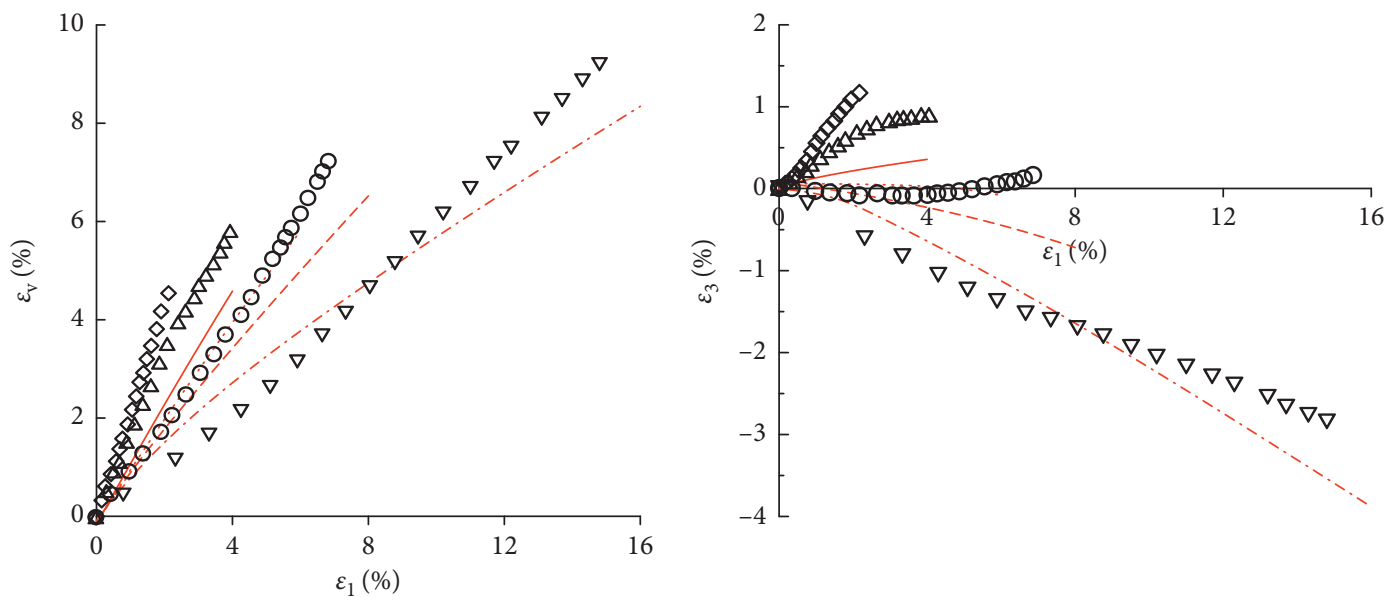

$\begin{array}{ll}\text { Prediction } & \text { Experiment } \\ - & \diamond R=1.5 \\ \ldots . . & \Delta R=2.0 \\ --- & \bigcirc R=2.5 \\ -.- & \nabla R=3.5\end{array}$

(c)

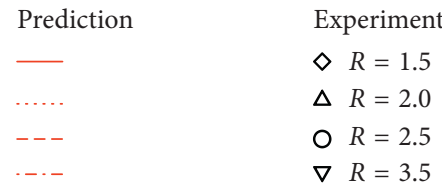

(d)

FIGURE 11: Predicted results of modified generalized plasticity model for CR test. (a) Spherical stress-volume strain curve. (b) Deviatoric stress-deviatoric strain curve. (c) Volumetric strain-axial strain curve. (d) Radial strain-axial strain curve.

phenomenon also exist in other generalized plasticity model, such as Zhu Sheng's unified generalized plasticity model [12] and Chen's model [13] considering particle breakage.

There are two main reasons for above prediction results: firstly, when using Fortran to predict the strain of constant stress ratio test, the stress control is adopted. The strain increment is obtained by flexibility matrix for given stress increment, and the strain is gradually accumulated. Because of simultaneous axial and radial loading of constant stress ratio test, dilatancy (contraction) law of actual test is different from that under conventional triaxial loading. However, in the process of prediction, the dilatancy equation of CT test is still used, which will underestimate the shearing property of rockfill under constant stress ratio test. Thus, the predicted volume strain is smaller and the deviator strain is larger under constant stress ratio loading, and the predicted radial strain is much smaller accordingly.

Secondly, some parameters in the generalized plasticity model cannot be determined by isotropic 
compression test, which are achieved by immune optimization algorithm. This optimization algorithm is mainly based on the triaxial loading condition by matching prediction and experiment results and has a certain degree of artificiality. If the number of inversed parameters is relatively large, it reflects the comprehensive influence of multiple parameters and also produces some errors. These reasons lead to the unsatisfactory radial strain predicted by the generalized plasticity model, and the dilatancy equation under constant stress ratio loading needs to be improved.

According to the above results comparisons, it can be seen that the law of dilatancy (shrinkage) of CR test is different from that of CT test. It is assumed that

$$
\frac{d \varepsilon_{\mathrm{v}}^{\mathrm{p}}}{d \varepsilon_{\mathrm{s}}^{\mathrm{p}}} \approx \frac{d \varepsilon_{\mathrm{v}}}{d \varepsilon_{\mathrm{s}}} .
$$

By analyzing and comparing the data of CT test and CR test, the dilatancy equation can be modified as follows:

$$
\begin{gathered}
\frac{d \varepsilon_{\mathrm{v}}^{\mathrm{p}}}{d \varepsilon_{\mathrm{s}}^{\mathrm{p}}}=\delta(R)(1+\alpha)\left(M_{\mathrm{g}}-\eta\right), \\
\delta(R)= \begin{cases}1, & R \geq 2.6, \\
\frac{k_{1}}{R}-k_{2}, & 1 \leq R \leq 2.6,\end{cases}
\end{gathered}
$$

where $R=d \sigma_{1} / d \sigma_{3}, \delta(R)$ is the correction coefficient, $\alpha$ and $M_{\mathrm{g}}$ are the same as modified generalized plasticity model, and both $k_{1}$ and $k_{2}$ are the dilatancy parameters of CR test.

For granite rockfills test, it can be finally obtained that $k_{1}=13.52$ and $k_{2}=4.09$. Under the conventional triaxial condition: $d \sigma_{3}=0, R \longrightarrow+\infty$, the correction coefficient $\delta(R)$ is equal to 1 , and the dilatancy equation degenerates to the dilatancy equation for the CT test. The modified coefficient defined by equation (11) shows that when $R \geq 2.6$, the dilatancy equation of CR test is same as that of $\mathrm{CT}$ test, ignoring the difference of dilatancy law between them; when $1 \leq R \leq 2.6$, the difference of dilatancy effect will be considered. The CR test results predicted by the modified dilatancy equation are shown in Figure 12. Compared with Figure 11, the prediction accuracy of the generalized plasticity model for CR test is obviously improved after the modified dilatancy equation is adopted, and CR test of rockfill materials can be well predicted.

\section{State-Dependent Extension of the Model}

Deformation characteristics of rockfill materials are affected not only by stress path but also by initial void ratio. The experiments of coarse-grained soils with different densities show that dense sand or rockfill has high strength, strong dilatancy, and even softening, while loose sand or rockfill has relatively low strength, weak dilatancy, and no softening. The generalized plasticity model proposed in this paper only predicts the stress-strain relationship of rockfill under specific density. If the same kind of rockfill has different experimental density, different model parameters will need to be sorted out. This approach treats rockfill with different experimental density as different materials. Such a model is obviously imperfect. With the continuous construction of dams in China, the influence of void ratio on dam materials deformation is gradually considered. Therefore, it is necessary to consider the influence of initial void ratio on the generalized plasticity model and extend the model to the state-dependent situation.

Following the work by Li and Dafalias [23] and Xiao et al. $[17,18]$, if the state dependent is considered, the critical state equation need to be defined in the framework of the generalized plasticity model. At the same time, the shear elastic modulus, loading direction related parameters, flow direction related parameters, and plasticity modulus also need to be modified as follows:

$$
\begin{aligned}
G & =G_{0} \cdot \frac{(2.97-e)^{2} \sqrt{P p_{\mathrm{a}}}}{1+e}, \\
\psi & =e-e_{\mathrm{cs}}, \\
e_{\Gamma} & =e_{\mathrm{a}}+k_{\mathrm{a}} e_{0}, \\
e_{\mathrm{cs}} & =e_{\Gamma}-\lambda \ln p .
\end{aligned}
$$

where $G_{0}$ is the material parameter, $e$ is the void ratio, $p$ is the average pressure, $e_{\mathrm{a}}, k_{\mathrm{a}}$, and $\lambda$ are the critical state parameters. The critical void ratio $e_{\mathrm{cs}}$ is logarithmic form in equation (13), but it is not fixed and can be adjusted according to the different material characteristics.

Critical state stress ratio, loading direction, flow direction, and plastic modulus can be defined as

$$
\begin{aligned}
M_{\mathrm{cs}} & =\frac{6 \sin \psi_{\mathrm{c}}}{3-\sin \psi_{\mathrm{c}}}, \\
\psi_{\mathrm{c}} & =\psi_{0}-\lg \left(p / p_{\mathrm{a}}\right) \Delta \psi, \\
d_{\mathrm{g}} & =(1+\alpha)\left(M_{\mathrm{d}}-\eta\right), \\
d_{\mathrm{f}} & =(1+\alpha)\left(M_{\mathrm{p}}-\eta\right), \\
M_{\mathrm{d}} & =M_{\mathrm{cs}} \exp \left(k_{\mathrm{d}} \psi\right), \\
M_{\mathrm{p}} & =M_{\mathrm{cs}} \exp \left(-k_{\mathrm{p}} \psi\right), \\
H & =H_{0} p_{\mathrm{a}}\left(\frac{p}{p_{\mathrm{a}}}\right)^{\mathrm{m}}\left[1-\left(\frac{\eta}{M_{\mathrm{p}}}\right)^{\beta}\right] \exp \left(\frac{\gamma \eta}{M_{\mathrm{p}}}\right), \\
H_{0} & =H_{\mathrm{Lo}}\left(h_{1}-h_{2} e_{0}\right) .
\end{aligned}
$$

where $M_{c s}$ is the critical state stress ratio, $\psi_{0}$ and $\Delta \psi$ are the critical state stress ratio parameters, $\alpha, k_{\mathrm{d}}$ and $k_{\mathrm{p}}$ are the model parameters, and $H_{\mathrm{Lo}}, h_{1}$, and $h_{2}$ are the parameters determined by isotropic compression tests of rockfill materials with different void ratios. Because $M_{\mathrm{p}}$ in the correction coefficient $H_{1}$ changes with the state parameters $\psi$ during shearing, the expression of plastic 

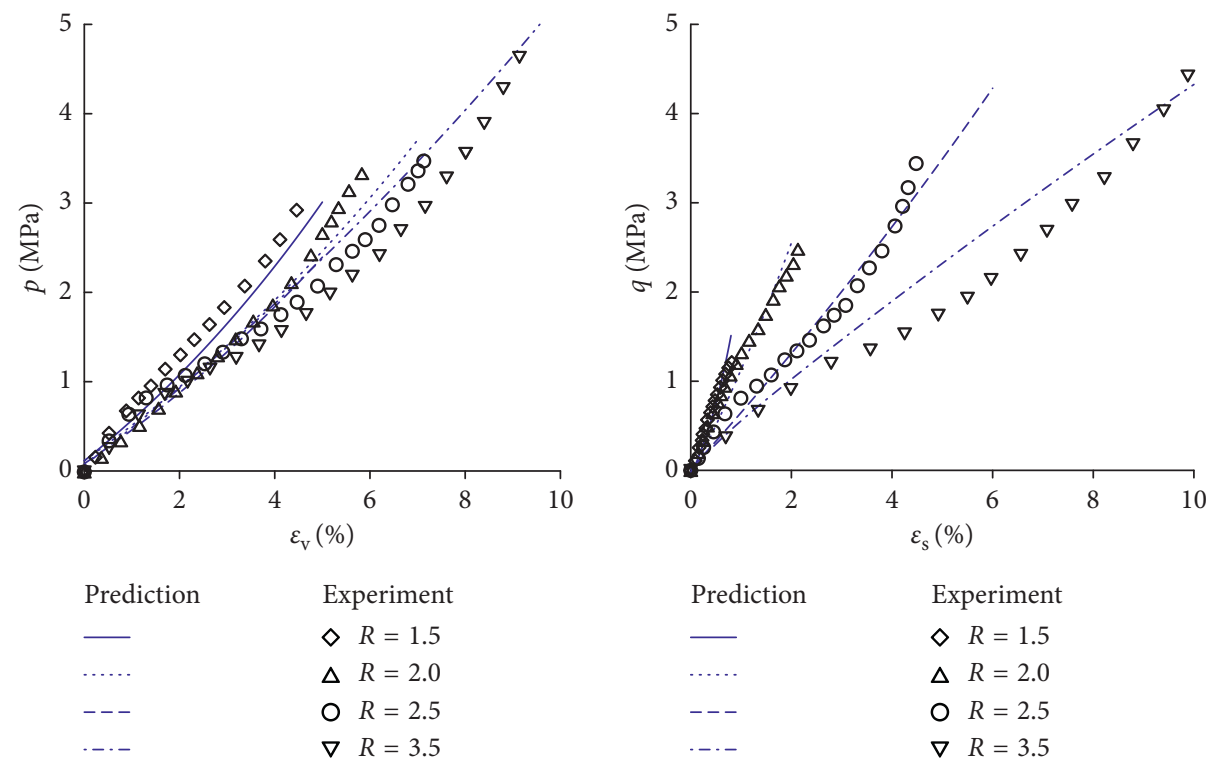

(a)
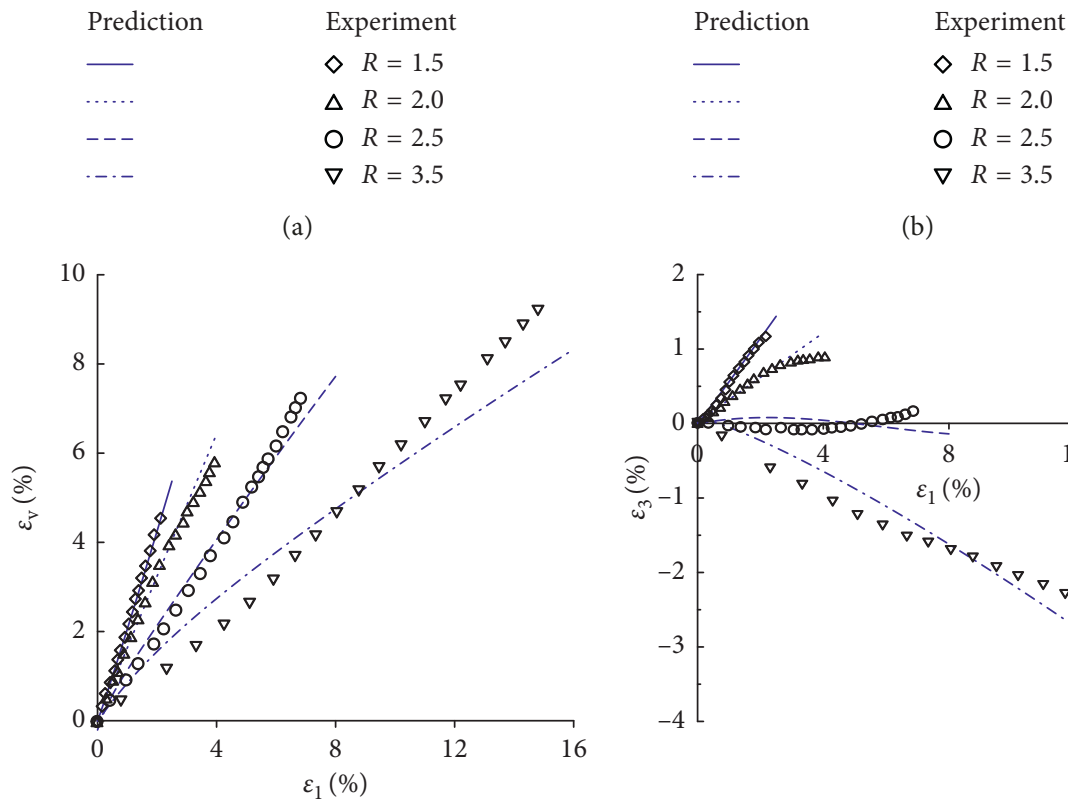

(b)
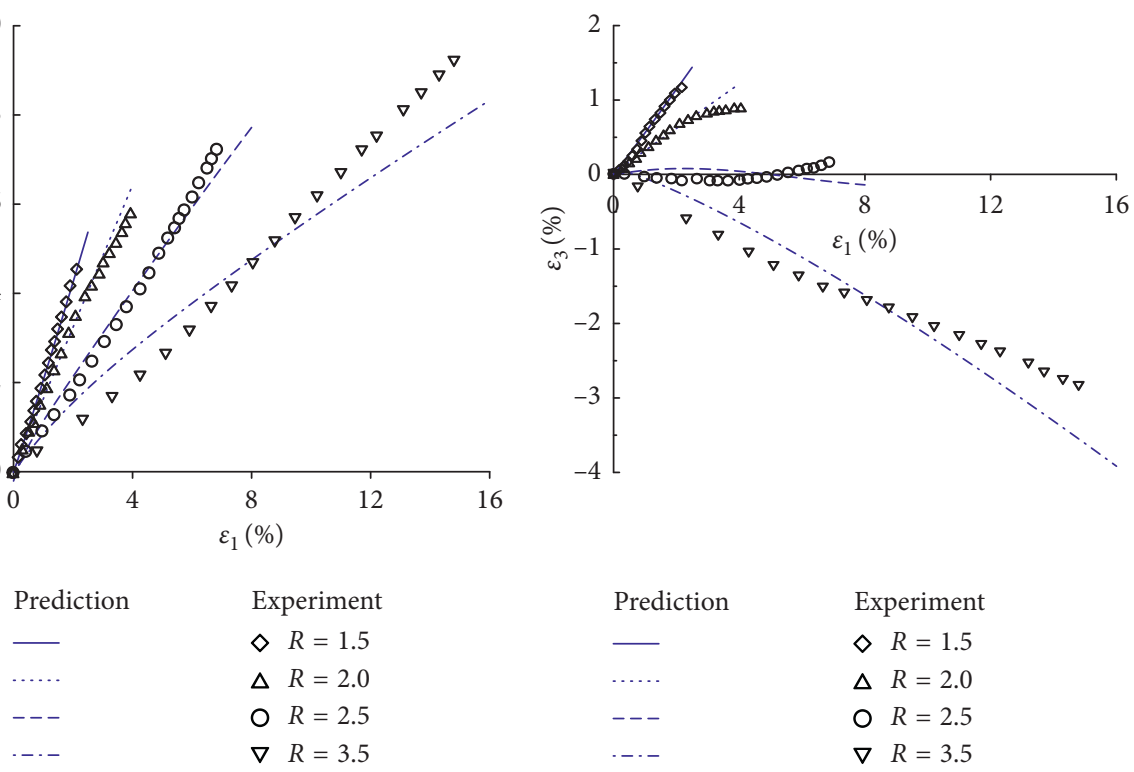

(c)

(d)

Figure 12: Prediction results of CR test based on improved dilatancy equation. (a) Spherical stress-volume strain curve. (b) Deviatoric stress-deviatoric strain curve. (c) Volumetric strain-axial strain curve. (d) Radial strain-axial strain curve.

modulus may be less than 0 , so softening phenomenon can be predicted.

Equation (18) mainly considers that the expression of plastic modulus can be reduced to that of isotropic compressive plastic modulus, and there are some differences in isotropic compressive tests of coarse-grained soil under different initial void ratios. Equation (18) is introduced to unify the effect of initial void ratio on plastic modulus. It is noteworthy that in equation (18), $e_{0}$ refers to the initial void ratio, which is constant in actual treatment, while $e$ is void ratio, which varies with volumetric strain.
Most parameters of the model can be calibrated by calibrated $[17,18,23] . H_{\mathrm{Lo}}, h_{1}$ and $h_{2}$ in plastic modulus can be determined by reference $[17,18]$. For triaxial tests of granite rockfills [24] and TRM [17, 18] with different void ratios, calibrated model parameters can be shown in Table 3 .

Figures 13-15 show the result of triaxial test and model prediction for granite rockfills under different confining pressures and void ratios. Figure 16 shows the result of TRM rockfill prediction. For granite rockfill, the generalized plasticity model can predict the strength characteristics of rockfill with different void ratio very well. 
TABLE 3: State-dependent generalized plasticity model parameters.

\begin{tabular}{|c|c|c|c|c|c|c|c|c|c|c|c|c|c|c|c|c|}
\hline Test & $G_{0}$ & $v$ & $e_{\mathrm{a}}$ & $\lambda$ & $k_{\mathrm{a}}$ & $\psi_{0}$ & $\Delta \psi$ & $\alpha$ & $k_{\mathrm{d}}$ & $k_{\mathrm{p}}$ & $H_{0}$ & $m$ & $\beta$ & $\gamma$ & $h_{1}$ & $h_{2}$ \\
\hline Jia & 310 & 0.2 & 0.252 & 0.02 & 0.713 & 49.5 & 6.5 & -0.2 & 1.0 & 0.2 & 1000 & 0.42 & 0.36 & 1.2 & 2.06 & 2.88 \\
\hline Xiao.et al & 127 & 0.2 & 0.53 & 0.057 & 0.59 & 51.7 & 7.9 & 0.2 & 0.2 & 3.89 & 740 & 0.48 & 0.74 & 0.0 & 3.44 & 8.51 \\
\hline
\end{tabular}

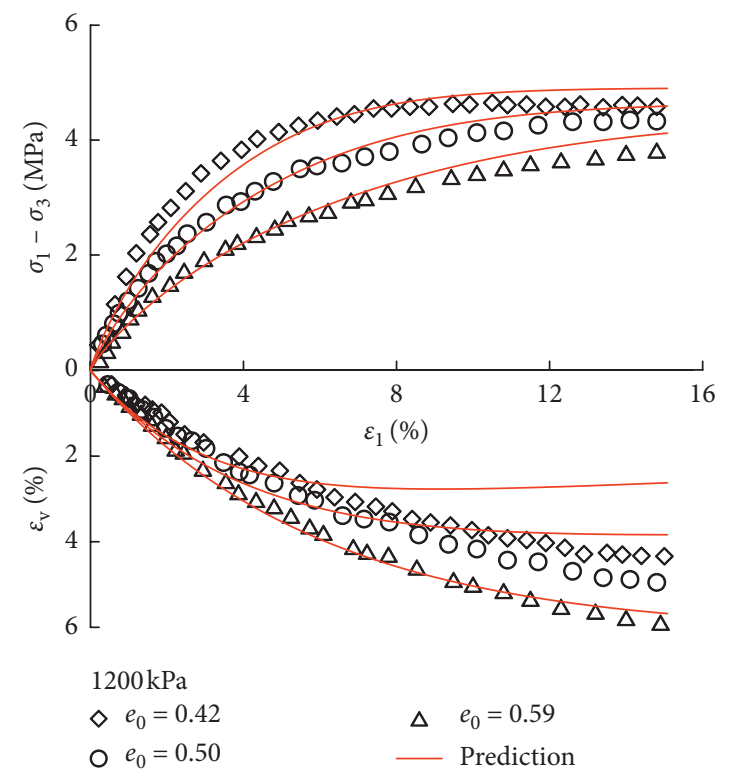

FIGURE 13: Experiment result and prediction of rockfill materials under $1200 \mathrm{kPa}$ confining pressure with different void ratios.

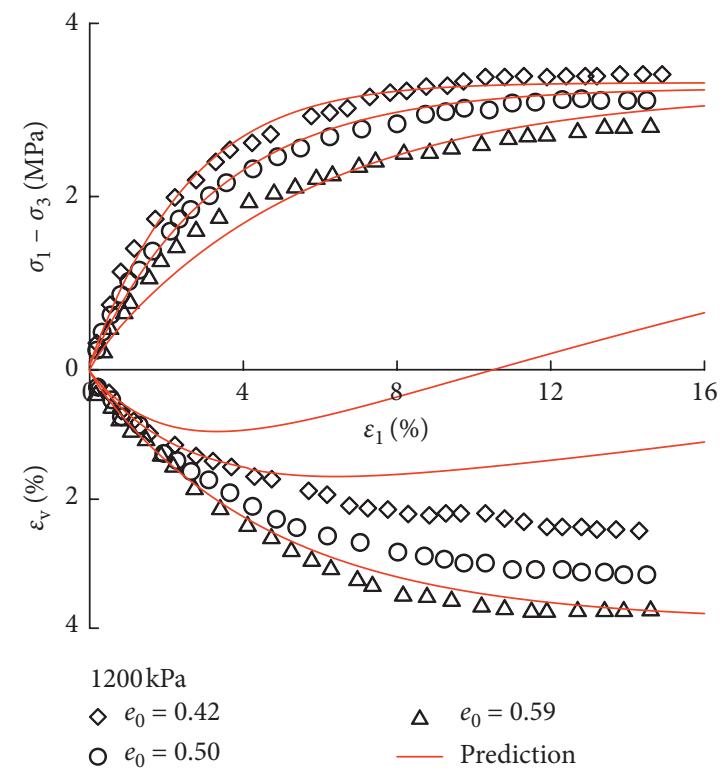

FIGURE 14: Experiment result and prediction of rockfill materials under $800 \mathrm{kPa}$ confining pressure with different void ratios.

The triaxial experiment of granite rockfills is not systemic, relatively rough, especially lack of critical state test data involved. It is hard to precisely calibrate the critical state parameters and dilatancy parameters. The prediction result of volumetric strain is of some deviation. For TRM rockfill test, due to the comprehensive test data, the state-dependent model can predict the triaxial test results of rockfill with various void ratios well. Generally speaking, the generalized plasticity model can reasonably capture the state dependence of coarse-grained soil. 


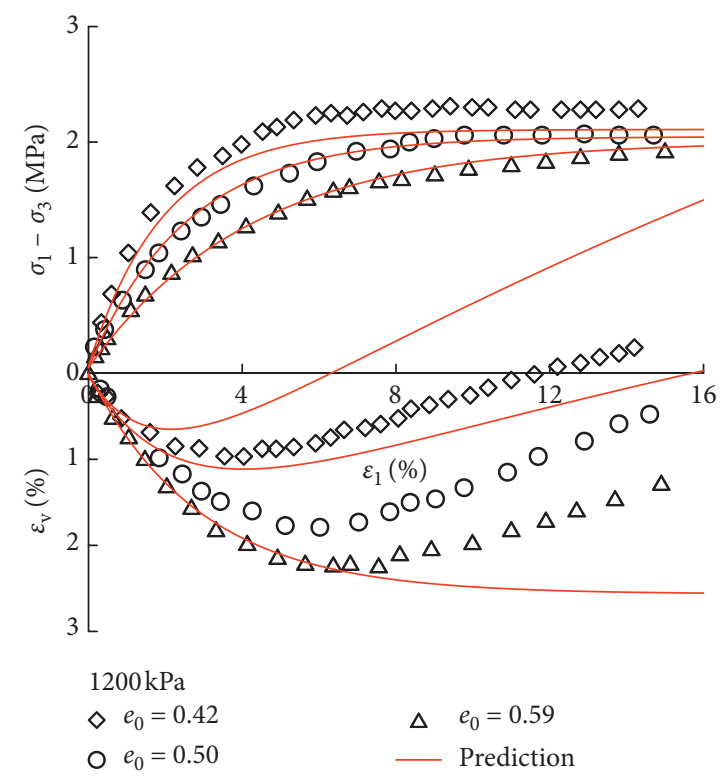

FIGURE 15: Experiment result and prediction of rockfill materials under $500 \mathrm{kPa}$ confining pressure with different void ratios.
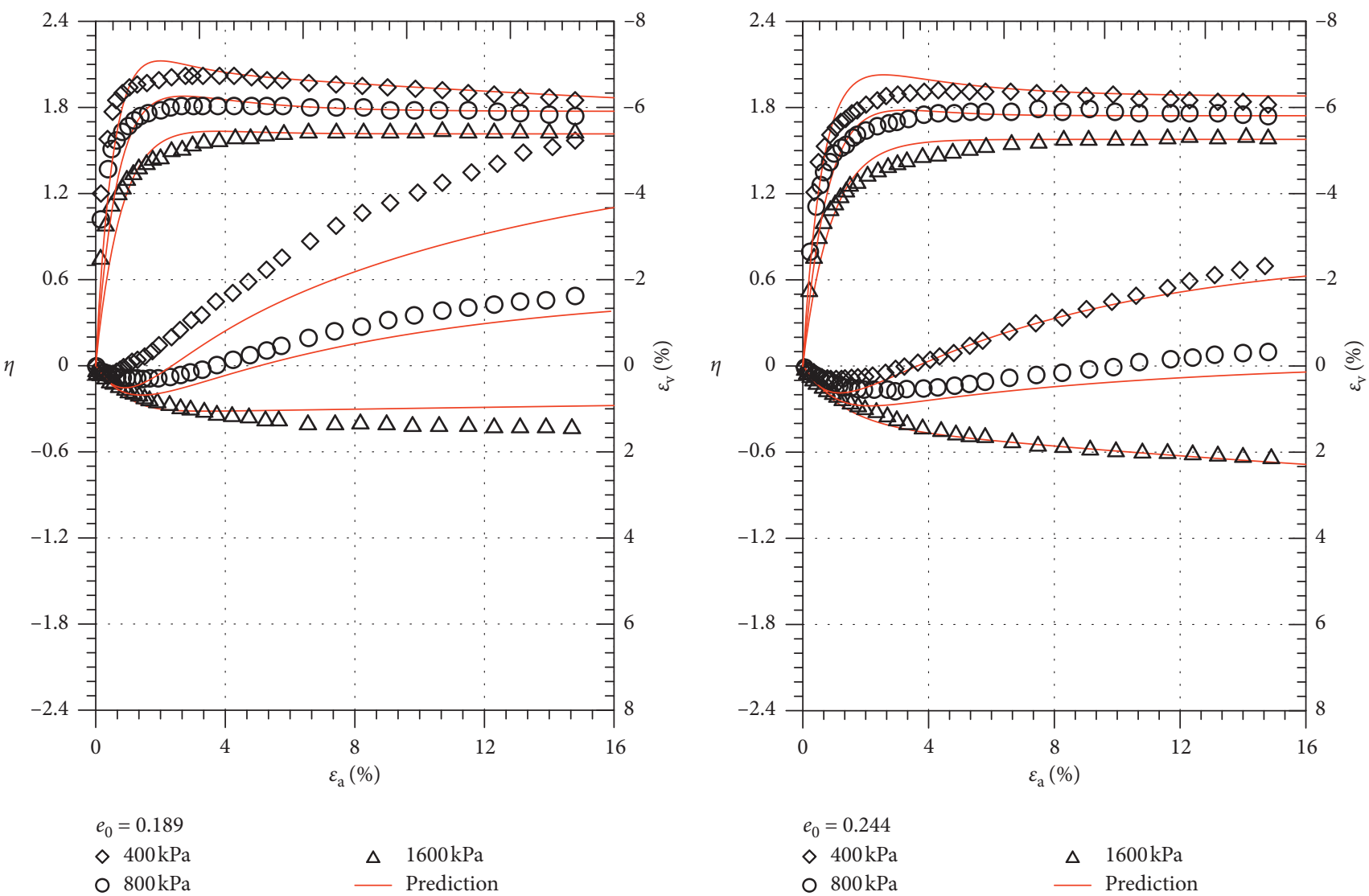

(a)

(b)

Figure 16: Continued. 

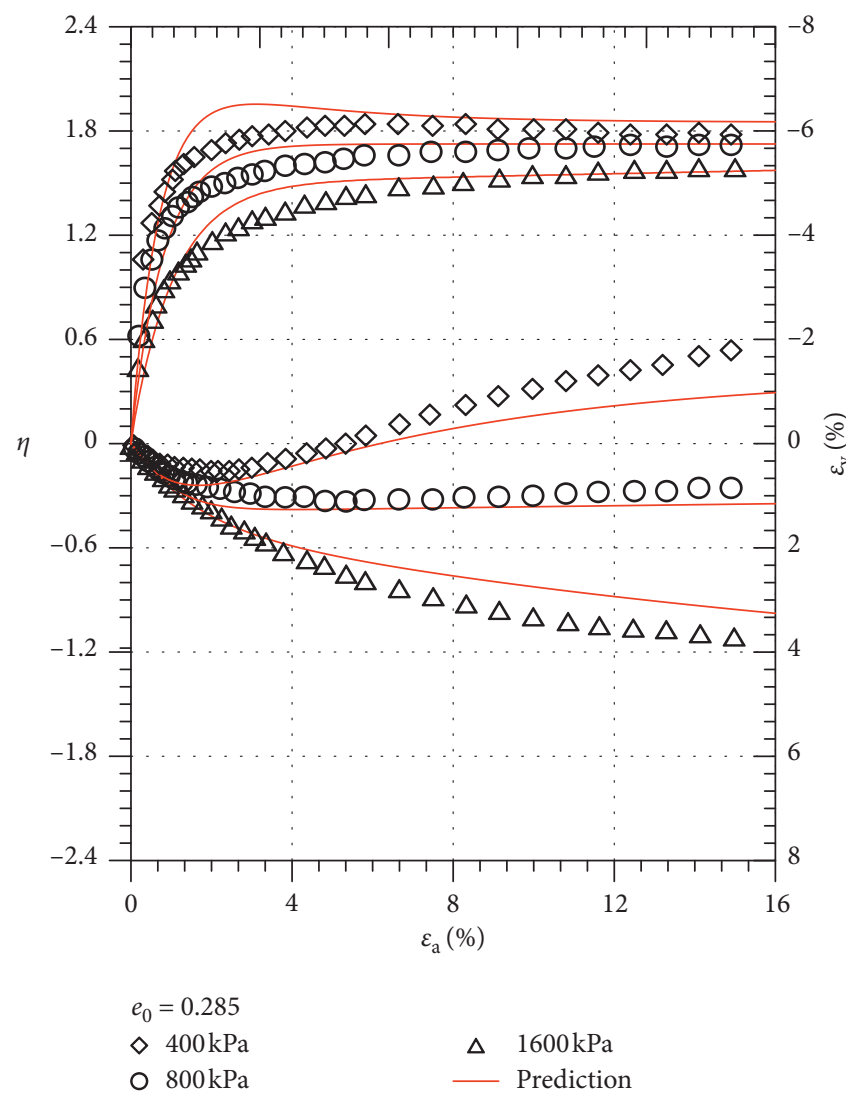

(c)

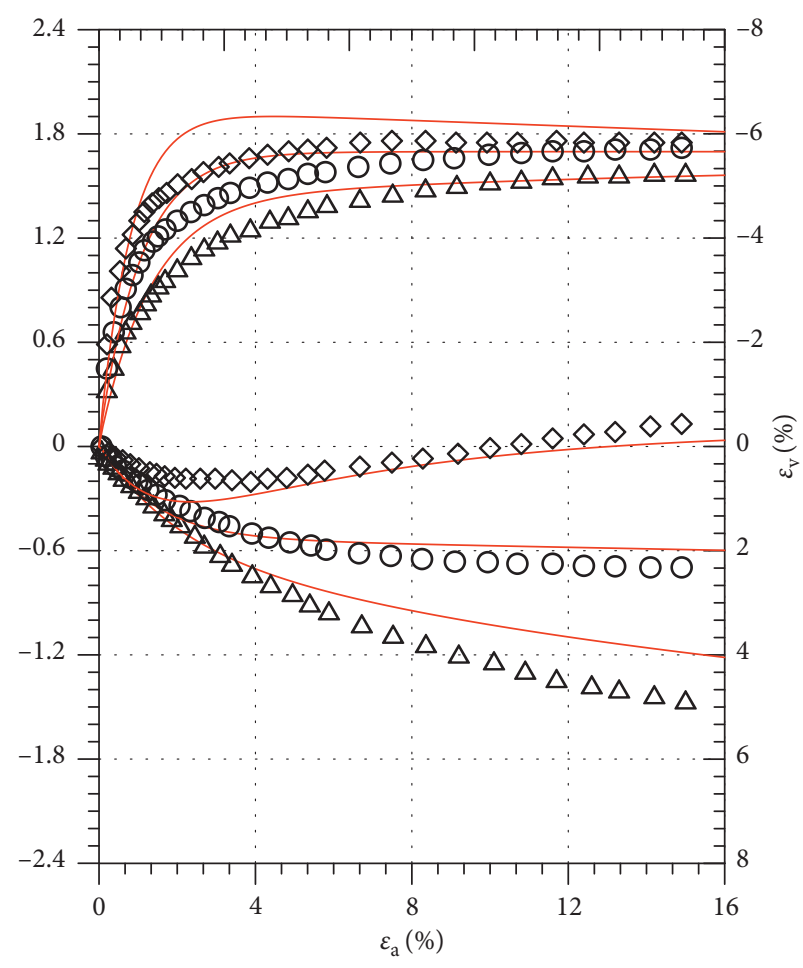

$e_{0}=0.317$

$\diamond 400 \mathrm{kPa}$

○ $800 \mathrm{kPa}$ $\triangle 1600 \mathrm{kPa}$

— Prediction

(d)

FIGURE 16: Experiment result and prediction of TRM with different void ratios. (a) $e_{0}=0.189$. (b) $e_{0}=0.244$. (c) $e_{0}=0.285$. (d) $e_{0}=0.317$.

\section{Conclusion}

By modifying the plastic modulus, a modified generalized plasticity model is established and verified by triaxial tests of rockfill materials. Basing on three kinds of stress path loading tests (CT test, CP test, and CR test), stress path adaptability of the generalized plasticity model is studied. The proposed model is also extended to capture the statedependent behaviors of rockfill materials. These works allow the following conclusions to be drawn:

(1) In the framework of generalized plasticity model, the modified coefficient and the plastic modulus are introduced to modify the generalized plasticity model. A modified generalized plasticity model for rockfill materials is suggested. The modified model improves the poor adaptability of original model under high confining pressure. The proposed model has fewer parameters and is easy to calibrate model parameters. The plastic modulus can be degenerated to isotropic compressive plastic modulus.

(2) The modified generalized plasticity model has good adaptability under conventional loading stress path. The model can predict the strength of CP test reasonably, while volumetric strain prediction is relatively smaller. The modified generalized plasticity model can hardly predict strain response under simultaneous radial loading and axial unloading effectively.

(3) The generalized plasticity model can hardly predict the larger radial strain, and the dilatancy equation under the conventional triaxial test is not suitable for the equal stress ratio test. Considering the effect of stress path on the dilatancy equation, an improved dilatancy equation is proposed. In the framework of the generalized plasticity model, the modified dilatancy equation can significantly improve the prediction accuracy of the equal stress ratio test of rockfill materials.

(4) Basing on the critical state soil mechanics theory, the modified generalized plasticity model can be extended to capture state-dependent features of rockfill materials.

(5) Various generalized plasticity models are difficult to predict the strain law of $\mathrm{CP}$ test for coarse-grained soil, which needs special attention and further improvement. In addition, it is necessary to establish a unified dilatancy equation suitable for various stress paths. To deeply reveal the dilatancy characteristics of rockfill materials under different stress paths, applying discrete element method in coarse-grained 
soil experiment may be an effective approach in the future work.

\section{Data Availability}

All the data used to support the findings of this study are included within the article.

\section{Conflicts of Interest}

The authors declare that they have no conflicts of interest.

\section{Acknowledgments}

The work presented in this paper was sponsored by the National Natural Science Foundation of China (grant nos. 51678164 and 51478118) and Ministry of Water Resources special funds projects of China (201501035). These financial supports are gratefully acknowledged.

\section{Supplementary Materials}

Data provided in the supplementary materials are files used in this paper. (Supplementary Materials)

\section{References}

[1] B. Xu, D. Zou, and H. Liu, "Three-dimensional simulation of the construction process of the Zipingpu concrete face rockfill dam based on a generalized plasticity model," Computers and Geotechnics, vol. 43, pp. 143-154, 2012.

[2] D. Zou, B. Xu, X. Kong, H. Liu, and Y. Zhou, "Numerical simulation of the seismic response of the Zipingpu concrete face rockfill dam during the Wenchuan earthquake based on a generalized plasticity model," Computers and Geotechnics, vol. 49, pp. 111-122, 2013.

[3] K. Wei and S. Zhu, "A generalized plasticity model to predict behaviors of the concrete-faced rock-fill dam under complex loading conditions," European Journal of Environmental and Civil Engineering, vol. 17, no. 7, pp. 579-597, 2013.

[4] W. Dong, L. Hu, Y. Z. Yu, and H. Lv, "Comparison between Duncan and Chang's EB model and the generalized plasticity model in the analysis of a high earth-rockfill dam," Journal of Applied Mathematics, vol. 2013, Article ID 709430, 12 pages, 2013.

[5] Z. Fu, S. Chen, and C. Peng, "Modeling cyclic behavior of rockfill materials in a framework of generalized plasticity," International Journal of Geomechanics, vol. 14, no. 2, pp. 191-204, 2014.

[6] M. Goorani and A. Hamidi, "A generalized plasticity constitutive model for sand-gravel mixtures," International Journal of Civil Engineering, vol. 13, no. 2, pp. 133-145, 2015.

[7] M. Liu and Y. Gao, "Constitutive modeling of coarse-grained materials incorporating the effect of particle breakage on critical state behavior in a framework of generalized plasticity," International Journal of Geomechanics, vol. 17, no. 5, article 04016113, 2017.

[8] W. J. Cen, J. R. Luo, E. Bauer, and W. D. Zhang, "Generalized plasticity model for sand with enhanced state parameters," Journal of Engineering Mechanics, vol. 144, no. 12, article 04018108, 2018.

[9] H. Abioghli and A. Hamidi, "A constitutive model for evaluation of mechanical behavior of fiber-reinforced cemented sand," Journal of Rock Mechanics and Geotechnical Engineering, vol. 11, no. 2, pp. 349-360, 2019.

[10] M. Pastor, O. C. Zienkiewicz, and A. H. C. Chan, "Generalized plasticity and the modelling of soil behaviour," International Journal for Numerical and Analytical Methods in Geomechanics, vol. 14, no. 3, pp. 151-190, 1990.

[11] H. I. Ling and S. Yang, "Unified sand model based on the critical state and generalized plasticity," Journal of Engineering Mechanics, vol. 132, no. 12, pp. 1380-1391, 2006.

[12] S. Zhu, K.-M. Wei, and D.-T. Lin, "Generalized plasticity model for soil and coarse-grained dam materials," Chinese Journal of Geotechnical Engineering, vol. 36, no. 8, pp. 1394-1399, 2014.

[13] S. S. Chen, Z. Z. Fu, H. Q. Han, and C. Peng, "An elastoplastic model for rockfill materials considering particle breakage," Chinese Journal of Geotechnical Engineering, vol. 33, no. 10, pp. 1489-1495, 2011.

[14] Z. J. Wang, S. S. Chen, and Z. Z. Fu, "Dilatancy behaviors and generalized plasticity constitutive model of rockfill materials," Rock and Soil Mechanics, vol. 36, no. 7, pp. 1931-1938, 2015.

[15] D. G. Zou, M. Fu, J. M. Liu, and X-j. Kong, "Study of adaptability of generalized plastic model of coarse grained soil under various stress paths," Journal of Dalian University of Technology, vol. 53, no. 5, pp. 702-709, 2013.

[16] E. L. Liu, S. S. Chen, G. Y. Li et al., "Critical state of rockfill materials and a constitutive model considering grain crushing," Rock and Soil Mechanics, vol. 32, no. S2, pp. 148-154, 2011.

[17] Y. Xiao, H. Liu, Y. Chen, J. Jiang, and W. Zhang, "Testing and modeling of the state-dependent behaviors of rockfill material," Computers and Geotechnics, vol. 61, no. 3, pp. 153-165, 2014.

[18] Y. Xiao, H. Liu, Y. Chen, and J. Jiang, "State-dependent constitutive model for rockfill materials," International Journal of Geomechanics, vol. 15, no. 5, article 04014075, 2015.

[19] S. Zhu, Y.-m. Wang, and X.-q. Hu, "Application of immune genetic algorithm to back analysis for parameters in model of rockfill dam coarse grain materials," Rock and Soil Mechanics, vol. 31, no. 3, pp. 961-966, 2010.

[20] B. Xiang, Z.-1. Zhang, and S.-c. Chi, "An improved hypoplastic constitutive model of rockfill considering effect of stress path," Journal of Central South University of Technology, vol. 16, no. 6, pp. 1006-1013, 2009.

[21] Nanri Group Corporation, Year-End Monitoring System Summary and Analysis Report of Sanbanxi Hydropower Dam and Discharge Structure, Nanri Group Corporation, Nanjing, China, 2008.

[22] G. Yang, X. Sun, Y.-z. Yu, and B.-y. Zhang, "Experimental study of mechanical behavior of a coarse-grained material under various stress paths," Rock and Soil Mechanics, vol. 31, no. 4, pp. 1118-1122, 2010.

[23] X. S. Li and Y. F. Dafalias, "Dilatancy for cohesionless soils," Geotechnique, vol. 50, no. 4, pp. 449-460, 2010.

[24] H. Jia, Study of loading and unloading properties of coarsegrained soils and adaptability of Duncan-Chang model, Ph.D. dissertation, Hohai University, Nanjing, China, 2012. 


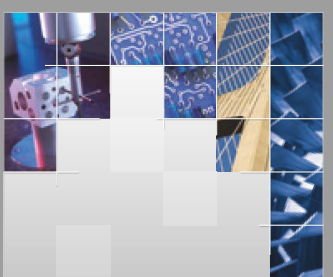

\section{Enfincering}
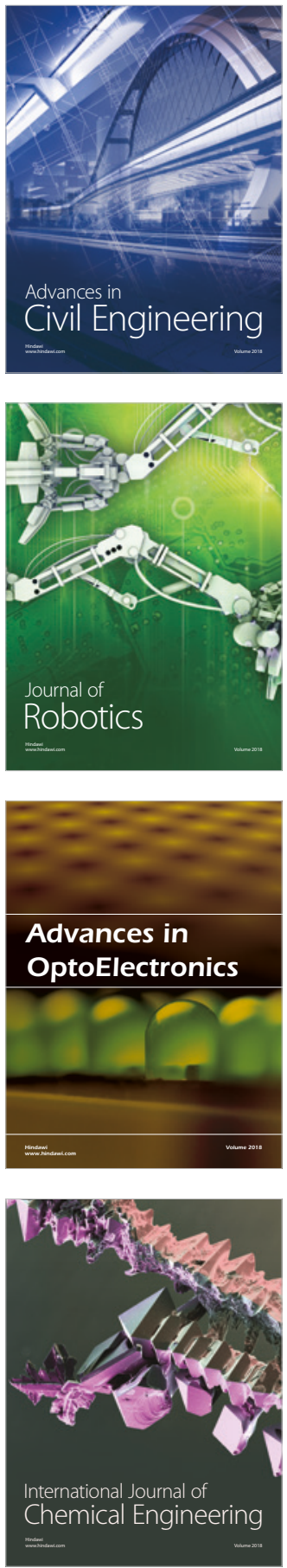

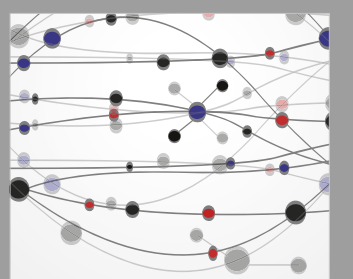

\section{Rotating \\ Machinery}

The Scientific World Journal

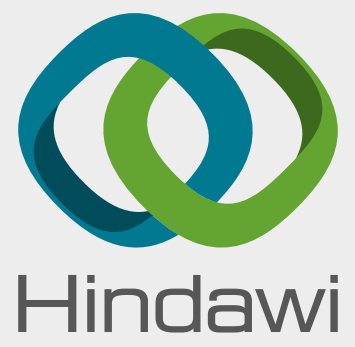

Submit your manuscripts at

www.hindawi.com
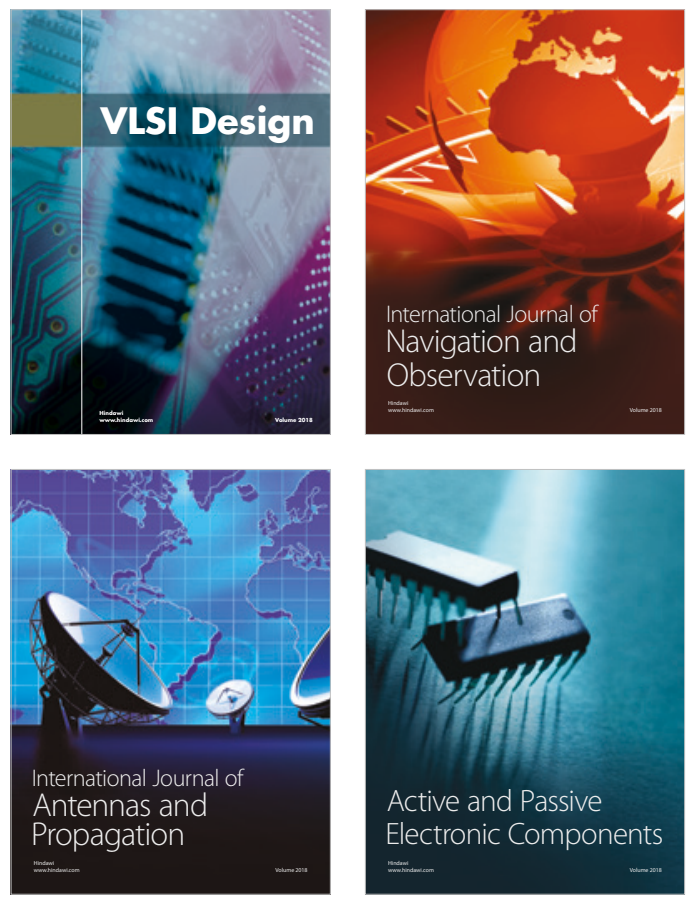
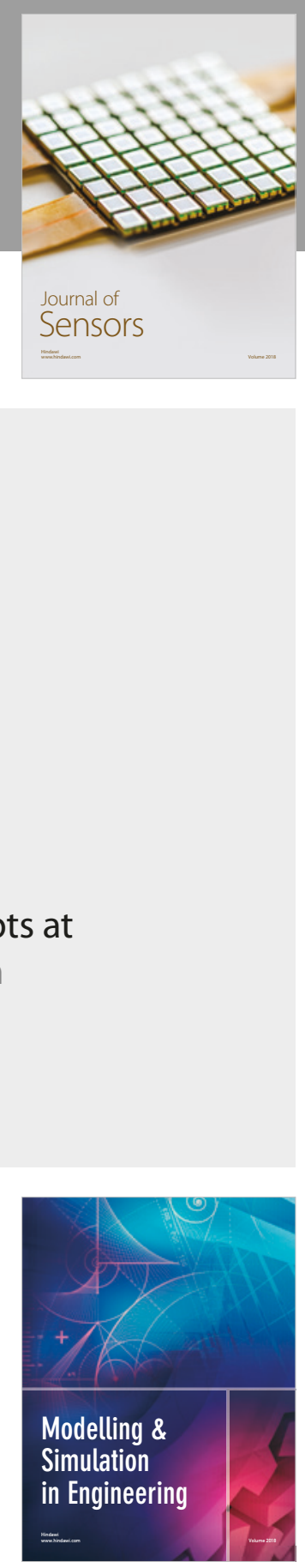

\section{Advances \\ Multimedia}
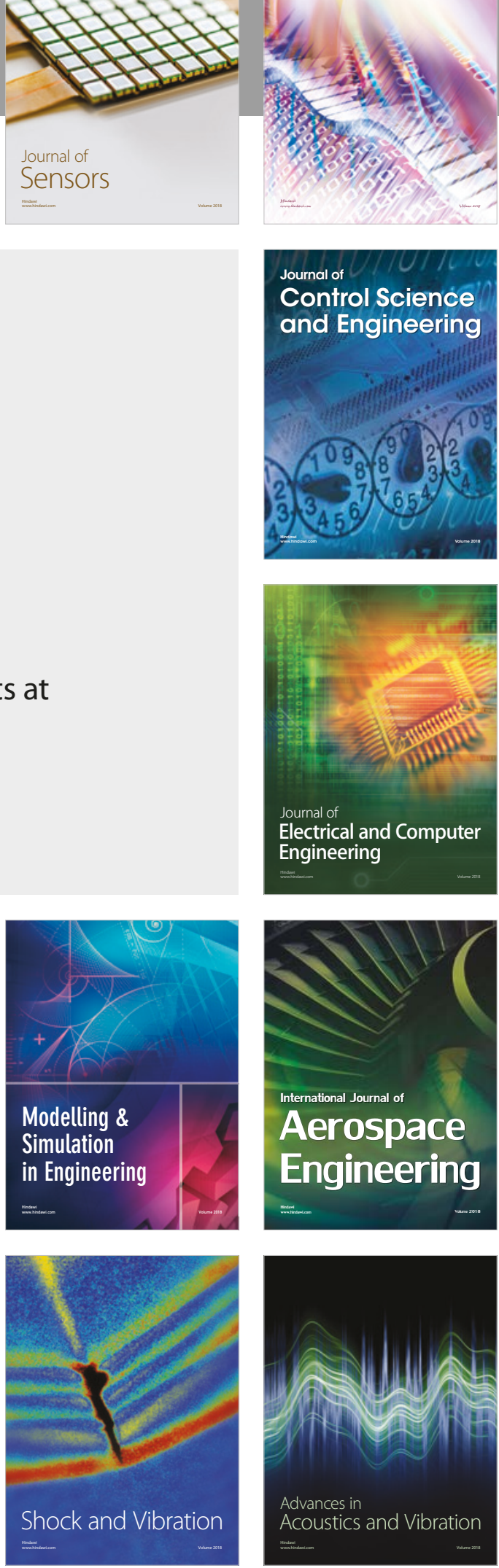